\title{
The Extent to which Risk Identification leads to Project Performance of Small and Medium Contractors in Gauteng, South Africa.
}

\author{
Nazeem Ansary ${ }^{1}$ and Berenger Yembi Renault ${ }^{2}$
}

\begin{abstract}
Risk management has been acknowledged as an area of concern in the management of construction project risks. One of the critical phases of the risk management process is risk identification, for if risks are not identified, they can have an adverse impact on the successful completion of projects. There appears to be little evidence of studies highlighting the correlation between project risk identification and project performance in South Africa construction industry, especially among small and medium contractors. Therefore, the current study aims to investigate the extent to which project risk identification leads to project performance of SMEs construction project in Gauteng, South Africa. Data were collected through a questionnaire survey among SMEs who were conveniently sampled in Gauteng. Descriptive and inferential statistics were used to analyze data collect. Findings revealed that there is a positive significant relationship between project risk identification and project performance that project risk identification leads to project performance. This finding suggests the significance of the risk identification phase in the management of project risks.
\end{abstract}

Keywords - contractors, project performance, risk identification, South Africa

\section{Introduction}

Risk management (RM) is acknowledged as a key activity in project management in the pursuit to deliver successful construction projects. This is because these projects are associated with various risks which often jeopardize project performance. Given the importance of project RM in construction project, the efficiency of RM is expected to lead to project performance [1].

Nazeem Ansary, Dept of Construction Management \& Quantity Surveying University of Johannesburg South Africa

Berenger Y. Renault, Dept of Construction Management \& Quantity Surveying

University of Johannesburg

South Africa
Numerous studies [2] [3]; [4]; [5] on the effect of RM strategies on project performance have established that effective RM improves project performance by enhancing productivity. [6] Stated that, it is not enough for enterprises to have a good project plan or have a good monitoring and control systems in achieving project success but they should focus on constituting effective project RM strategies including risk identification, risk assessment risk responses, and risk monitoring and review to contribute to the success of the project. RM strategies must be carried out throughout the life cycle of the construction project, from initiation stage until the decommissioning of the project. Failure to manage the project risks throughout the life cycle of construction projects will lead to poor project performance [7]. [8] Stated that risk identification is the starting point of the RMP and is considered to be crucial as if risk is not identified, it will be almost impossible to respond to it effectively.

The use of effective RM strategies and especially risk identification is increasing and has been the center of focus recently in order to achieve construction project performance and also have emphasize on contractual obligations [9]. [3] Indicated that low implementation of project risk management strategies in practice causes the projects failure of many construction SMEs such as meeting deadlines, cost targets and quality performance. However, it is still inconclusive as to what extent does the risk identification lead performance of SMEs construction projects in South Africa thus the need to determine the effects of risk identification on SMEs construction project performance in South Africa. Achieving project performance forms, the basis to adoption and implementation of risk identification practices [4]. Project risk management strategy is embedded to organizational internal control and audit, a condition necessary for effective project risk management measures in the project [10]. This hence influences the enterprise management focus on project control and technological control which supports project requirements and governance to attain the success in project performance. Risk management strategies essentially influences the success of project performance [11]. This is so because effective risk management strategies and successful project performance has an intimate relationship. For instance, risk identification identified the potential risks that might influence the project objectives [12]. [13] stated that if risk events are not handled and managed properly, consequences such as increasing the financial costs, changing the capital structure, delaying the building or facility operations, overrun in the budget, loss of cash inflow, lead to liquidated damages claims, production of poor quality end product, project rework after completion and so on might occur. Therefore, mitigation actions against these 
risks and uncertainties are vital to ensure achievement of the desired project performance. Due to the long development of lead-times, rising development costs and high failure rate for construction SMEs projects, project risk identification is important to the SME in construction industry to influence project performance [2]. SMEs project presents a level of risks and management adopts project risk management strategies to influence achievement of the project performance.

\section{A. Research objectives}

The main objective of this study was to investigate the extent to which risk identification leads to project performance of construction small and medium enterprises in Gauteng, South Africa. In order to achieve the main objectives, specific objectives were formulated as follows:

- To determine the current level of project risk identification as carried out by construction SMEs in Gauteng;

- To determine the extent to which SMEs undertake risk identification for the purpose of mitigating the risks encountered in their projects; and

- To rate the importance of risk identification practices in project risk management in the enterprises.

\section{Literature review}

\section{A. Project performance}

Over the years, numerous studies have been conducted on project success, and most of them have suggested various dimensions for measuring project success. [14] Opined that project success is contrastingly viewed among researchers and practitioners. The conventional measures of time, cost, and quality known as the Iron triangle have been the leading success metrics in construction [15]. The Iron triangle is cited in nearly every study [16]; [17]; [18]; [19] on project success. Contrariwise, [13] posited that project success should not be limited to just the Iron triangle and the project management community need to be informed about this. [15] Indicated that while other definitions of project success have emerged, the iron triangle is constantly cited in the unconventional definitions.

In addition to the conventional measures, [20] supported that dimensions for project success should also encompass project psychosocial outcomes which involve the contentment of interpersonal relations with the project team. Individual dimensions such as participants' satisfaction level are referred to as soft dimensions. The incorporation of satisfaction as a success metric is recommended by [21]. [22] Further suggested incorporating the absence of legal claims as a measure of project success. This indicates the importance of including safety as a success measure since it is logical to anticipate that if accidents materialize, both clients and contractors may be subject to financial loss, contract delay as well as legal claims. [23] Assessed project success extensively based on five criteria namely; maintenance cost, construction cost, time, safety and flexibility to users. [24] Stated that it is problematic to evaluate whether the performance of a project is a success or a failure owing to the fact that the notion of success remains unclear amongst project participants. According to [25], the project is a complete success if it attains the technical performance specifications to be executed, and if there is satisfaction regarding the project outcome among key users and project team members. In evaluating project success, [26] included a range of criteria which included project meeting planned cost, time, quality of work, affability of the environment, transfer of technology, client and project manager's satisfaction, and health and safety. [26] Defined project success based on four measures namely; achieving design goals, the value to the end user, the value to the organization, the value of the technological infrastructure of the country and of organizations implicated in the development process. All these measures combined together provide the inclusive evaluation of project success.

Regardless of the controversy in defining project success, this study follows the definition of project success as per [27]; [23]; [26]. This implies that the measures used in the study reflect project performance [16] [17]. [26] Posited that the utilization of a set of project success measures gives a considerable evidence of project performance than focusing on a single measure or a minor number of unplanned measures.

\section{B. Relationship of risk identification with project success}

The results of [28] indicated that risk identification influenced project success. Similarly, [29], in their study observed that some authors ([30];[31];[32], observed that, as management involvement increases in risk identification, the risk of unclear or misunderstood scope seems to lessen and improve project performance and hence influence positively project outcome. A study conducted by [31] indicated that individual RM activity, risk identification, contributes to project success. They further inferred that the interaction through discussion between project members during risk identification has a positive impact on the perceived success of the project. From the above discussion, it can be said that there is a relationship between risk identification and project performance.

\section{Conceptual framework for the study}

Figure 1 represents the theoretical conceptual framework proposed in the study. The framework depicts the influence of the independent variable on the dependent variable. On the other hand, project performance is dependent on the level of practice of the factor namely; project risk identification. 1) Risk reporting; 2) risk registration; 3) risk allocation; 4) risk 
control; and 5) risk checklist were employed as the variables of project risk identification. The relationship between the variables is discussed in section II.B. For project performance, maintained that time, cost and quality have been the leading success metrics of construction projects. However, [26] posited that project success should not be limited to just the traditional view. ${ }^{[1]}$ Further suggested incorporating the absence of legal claims as a measure of project performance. This indicates the importance of including safety as a success measure since it is logical to anticipate that if accidents and/or injury materialise. For the purpose of this study, time, cost, quality and health and safety were used as project performance variables.

Independent variable

Dependent variable

Project risk identification
1. Risk reporting
2. Risk registration
3.Risk allocation
4. Risk control
5. Risk checklist

Figure 1. Conceptual framework

\section{Methodology}

The population of the study comprised of top management of SMEs (mostly owners, owner-managers, managers and project managers) who were selected from the Construction Industry Development Board (CIDB) register of contractors. In identifying potential respondents, the researcher ensured that all respondents were graded 1 to 6 (indicating small and medium contractors) and that they had a valid registration with the body they were from in order to participate in the study. Both secondary and primary data were used in the study. An extensive review of literature was carried out to gather secondary data included in the questionnaire which was later pre-tested. Primary data on the other hand was collected by administrating a questionnaire, via personal hand delivery method. Following the questionnaire pre-testing, the final refined version of the questionnaire was distributed to 150 conveniently sampled SMEs using personal hand delivery and collect method of which 120 questionnaires were returned and were deemed usable representing $80 \%$ response rate.

SPSS version 23 was employed computing descriptive statistics, Exploratory Factor Analysis (EFA) and Multiple Regression Analysis (MRA). EFA was performed to gather information about the uni-dimensionality of the variables, to confirm their validity and reliability of the variables. MRA was conducted to ascertain the influence of project risk identification on project performance.

\section{Findings and discussion}

\section{A. Validity and reliability}

The measurement instrument was also tested for validity and internal consistency. Validity was ensured as a result of conducting an extensive literature review by consulting previous related studies, this was requisite to specify the variables. The questionnaire was reviewed and revised by experts before conducting the pilot study with the intended respondents.

Cronbach's Alpha was used to assess the reliability of the empirical constructs. A generally agreed upon minimum limit for Cronbach alpha is 0.70 [33]. However, a cut-off value of 0.60 is common for exploratory research and values closer to 1 suggest good reliability [34]. For this study, a cut-off value of 0.60 was adopted. The overall Cronbach's alpha of the factor was 0.867 and the one of each item ranged from 0.678 to 0.953 (Table 1). These were all greater than the suggested value of 0.60 , indicating good reliability of the constructs [34]. Reliability results are presented in Table 1.

Table 1. Cronbach's Alpha of empirical constructs
\begin{tabular}{|l|c|}
\hline \multicolumn{1}{|c|}{ Project risk identification variables } & $\begin{array}{c}\text { Cronbach's } \\
\text { alpha } 0.867\end{array}$ \\
\hline $\begin{array}{l}\text { Risk registration influence identification and } \\
\text { management of project risk }\end{array}$ & 0.953 \\
\hline $\begin{array}{l}\text { Use of checklist enhance risk identification in small } \\
\text { and medium technology firms }\end{array}$ & 0.785 \\
\hline $\begin{array}{l}\text { Risk controls enhance project risk identification } \\
\text { process }\end{array}$ & 0.776 \\
\hline $\begin{array}{l}\text { Screening of project risks and taking measure influence } \\
\text { project being completed within time }\end{array}$ & 0.678 \\
\hline $\begin{array}{l}\text { The enterprise undertakes risk allocation mitigating } \\
\text { occurrence of project loss }\end{array}$ & 0.804 \\
\hline $\begin{array}{l}\text { Risk registration is effectively influencing project } \\
\text { success }\end{array}$ & 0.904 \\
\hline $\begin{array}{l}\text { Increase in project risk reporting influence quality } \\
\text { achievement }\end{array}$ & 0.765 \\
\hline $\begin{array}{l}\text { Increasing of risk awareness hence mitigation of } \\
\text { project against incurring high costs }\end{array}$ & 0.835 \\
\hline $\begin{array}{l}\text { Effective risk management planning that reduces } \\
\text { project delays in achieve }\end{array}$ & 0.906 \\
\hline $\begin{array}{l}\text { Effective risk identification process enable } \\
\text { organization taking correct measures that influence } \\
\text { projects less costly }\end{array}$ & 0.773 \\
\hline
\end{tabular}

\section{B. Risk identification}

This section sought to determine the current level of project risk identification as carried out by construction SMEs. Respondents were asked to rate their project risk identification level from the scale 1=Low; $2=$ Medium; and $3=$ High. The findings are presented in Table 2.

Table 2. Level of risk identification as carried out in the enterprise

\begin{tabular}{|c|c|c|}
\hline & Frequency & Percent \\
\hline Low & 38 & 32 \\
\hline Medium & 11 & 9 \\
\hline High & 71 & 59 \\
\hline Total & 120 & 100.00 \\
\hline
\end{tabular}


The level of project risk identification as carried out in SMEs was deemed to be high (59\%). $32 \%$ of SMEs respondents indicated that there was a low level of project risk identification as carried out in SMEs the enterprise while 9\% of the respondents rated their project risk identification level to be medium in their enterprise. According to respondents, risks were identified to select appropriate mitigation measures for risk management. This indicates that identifying the risks encountered during construction project and selecting the strategy with the greatest risk/reward characteristics would lead to project success. This could be due to the importance of risk identification as the most influential process of risk management process, as reported by [28], who found that the identification of risks is the ultimate step that decides the end result of the project management process.

\section{B. Extent to which SMEs undertake risk identification}

SMEs respondents were required to rate the extent to which their enterprise undertook risk identification for the purposes of mitigating risk encountered in their projects. The results are illustrated in Figure 2.

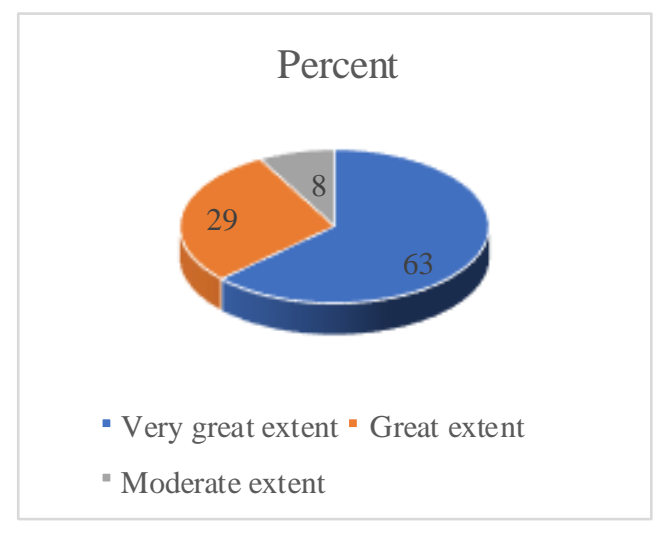

Figure 2. Extent to which enterprise undertake risk identification

It is shown that $63 \%$ of SMEs respondents indicated that their enterprise undertakes risk identification for the purposes of mitigating risk encountered in their projects to a very great extent. $30 \%$ of respondents indicated their undertake risk identification to a great extent while $8 \%$ indicate to undertake risk identification to a moderate extent. This signifies that the enterprises distinctive risk identification effort to influence achievement of project performance. This communication of identifying project risks was found as an appropriate way of risk mitigation thus influencing the project performance. The finding supported [31] who found that project risk identification was the most influential process in project management through communications of risk, reporting, risk registration and risk allocation, risk analysis and risk control at influencing project's performance.

\section{Importance of risk identification practices in project risk management}

SMEs respondents were asked to rate the importance of risk identification practices in project risk management in their enterprise. The results are presented in Table 3.

Table 3. Rating of risk identification practices in project risk management
\begin{tabular}{|l|l|l|l|}
\hline Risk identification Practices & Mean & SD & Z-scores \\
\hline $\begin{array}{l}\text { Risk management is established } \\
\text { throughout the whole enterprise }\end{array}$ & 4.71 & 0.87 & 2.672 \\
\hline Insuring against financial loss & 4.58 & 0.46 & 0.001 \\
\hline Develop risk management strategy & 4.40 & 0.44 & -1.131 \\
\hline
\end{tabular}

SD: Standard deviation.

Findings as presented reveal that the majority of the respondents indicated that risk management is established throughout the whole enterprise $(\mathrm{M}=4.71 ; \quad \mathrm{SD}=0.87)$. Respondents further raised the importance of insuring against financial loss $(\mathrm{M}=4.58 ; \quad \mathrm{SD}=0.46)$ and develop risk management strategy $(\mathrm{M}=4.40 ; \mathrm{SD}=0.44)$ to allocate resources efficiently and influence less costing of the project. The findings signify that risk identification plays an important role in the success of SMEs project risk management. The findings from Z-scores suggest that Z-score $(Z$-score $=0.001)$ was determined, indicating that it was centred on the mean and deviation from the standard deviation zero. The Z-score $=2.672$ however, signifies that most of SMEs respondents' responses falls above the mean. This is an indication that project risk identification had a significant positive impact of project performance. The finding is contrary to the result of the study conducted by [17] where it was revealed that it was not easy to undertake project risk identification being not sufficient for achieving comprehensive risk management and achieving project performance.

\section{$D$. Extent to which risk identification leads to project performance}

Table 4. Risk identification leads to project performance

\begin{tabular}{|l|l|l|l|}
\hline Risk identification practices & Mean & SD & Z-score \\
\hline $\begin{array}{l}\text { Risk registration influence identification and } \\
\text { management of project risk }\end{array}$ & 4.88 & 0.76 & 1.691 \\
\hline $\begin{array}{l}\text { Use of checklist enhance risk identification in } \\
\text { small and medium technology firms }\end{array}$ & 4.83 & 0.71 & 1.854 \\
\hline $\begin{array}{l}\text { Risk controls enhance project risk identification } \\
\text { process }\end{array}$ & 4.71 & 0.66 & 2.696 \\
\hline $\begin{array}{l}\text { Screening of project risks and taking measure } \\
\text { influence project being completed within time }\end{array}$ & 4.69 & 0.58 & 1.284 \\
\hline $\begin{array}{l}\text { The enterprise undertakes risk allocation } \\
\text { mitigating occurrence of project loss }\end{array}$ & 4.50 & 0.46 & 0.385 \\
\hline $\begin{array}{l}\text { Risk registration is effectively influencing } \\
\text { project success }\end{array}$ & 4.46 & 0.37 & 0.012 \\
\hline $\begin{array}{l}\text { Increase in project risk reporting influence } \\
\text { quality achievement }\end{array}$ & 4.33 & 0.35 & -0.461 \\
\hline $\begin{array}{l}\text { Increasing of risk awareness hence mitigation of } \\
\text { project against incurring high costs }\end{array}$ & 4.29 & 0.33 & -1.296 \\
\hline $\begin{array}{l}\text { Effective risk management planning that reduces } \\
\text { project delays in achieve }\end{array}$ & 4.24 & 0.31 & -0.423 \\
\hline $\begin{array}{l}\text { Effective risk identification process enable } \\
\text { organization taking correct measures that } \\
\text { influence projects less costly }\end{array}$ & 4.14 & 0.25 & -1.002 \\
\hline
\end{tabular}


Proc. of Eighth International Conference On Advances in Civil, Structural and Mechanical Engineering - ACSM 2018 Copyright $($ Institute of Research Engineers and Doctors, USA. All rights reserved.

ISBN: 978-1-63248-154-2 doi: 10.15224/978-1-63248-154-2-29

\section{E. Regression results}

The study sought determine the effects of project risk management strategies on the project performance of ICT SMEs in Kenya. The study sought to establish the extent to which the study variable project risk identification impact on project performance of SMEs. The findings on regression analyses are presented in Table 5.

Table 5. Model summary

\begin{tabular}{|l|l|l|l|l|l|}
\hline Model & $\mathrm{R}$ & $\begin{array}{l}\mathrm{R} \\
\text { Square }\end{array}$ & $\begin{array}{l}\text { Adjusted } \\
\text { Square }\end{array}$ & $\begin{array}{l}\text { Std. Error of the } \\
\text { Estimate }\end{array}$ & $\begin{array}{l}\text { Sig } \\
\text { change }\end{array}$ \\
\hline 1 & $\begin{array}{l}0.814 \\
\text { (a) }\end{array}$ & 0.649 & 0.637 & 0.36 & 0.001 (a) \\
\hline
\end{tabular}

a Independent variable: risk identification

b Dependent variable: project performance

The correlation coefficient $\mathrm{R}$ was 0.649 with an adjusted $\mathrm{R}$ Square of 0.637 . These results indicate that the goodness of fit of the model was satisfactory, suggesting that the independent variable project risk identification contributes 63.7 percent of the variations in project performance.

\section{F. Analysis of variance (ANOVA)}

ANOVA test was conducted to determine whether the model had a good fit for the data. Results are presented in Table 6. The F Statistics of 5.192, with $p=0.01<0.05$ was an indication that the model formed between project risk identification and project performance was significant. The $\mathrm{F}=$ 5.192 value was greater than the $\mathrm{F}$ critical value of 0.105 . These results established that there is a significant strong positive variation between the independent variable, project risk identification and the dependent variable, project performance at 0.01 significant levels. This results further shows that project risk identification is good predictor of project performance.

Table 6. ANOVA results (b)

\begin{tabular}{|l|l|l|l|l|l|l|}
\hline Model & Sum of Squares & Df & Mean Square & F-Test & Sig. \\
\hline 1 & Regression & 3.842 & 4 & 0.306 & 5.192 & 0.01 (a) \\
\hline & Residual & 33.158 & 74 & 0.58 & & \\
\hline & Total & 37.000 & 78 & & & \\
\hline
\end{tabular}

a Independent variable; Project risk identification

b Dependent variable: Project performance

\section{v. Conclusion}

The main objective of the study was to investigate the extent to which risk identification leads to project performance of small and medium enterprises in Gauteng, South Africa. Through a questionnaire survey among SMEs respondents in Gauteng, it was found that there is a positive significant impact of project risk identification on project performance, that risk identification leads to performance in construction projects of SMEs through risk registration, use of checklist, risk controls and screening of project risks influencing project success to a great extent and achievement of project goals. This because SME project risk identification and management by use of checklist, risk controls and screening of project risks reducing of project loss and development of quality in projects to a great extent.

Furthermore, it is evident that among SMEs' respondents there is general awareness of the risk identification practices as disclosed in literature. However, it is comprehensible that the awareness of these techniques does not assure that they are used by the organizations. This paper presents a variety remarkable contributions to RI in both theory and practice; nevertheless, numerous restraints of the study need to be recognized. The study was restricted to Gauteng, targeting construction SMEs hence, the results may not be representative of the whole country. A further study should be undertaken which will cover the entire country.

The study found a significant positive relationship between risk identification and project performance of construction SMEs hence, the study recommends that upper management of SME projects should increase level of project risk identification as it enhances the risk management activities. SME in construction facilitated a distinctive project risk identification effort as they undertook risk identification for the purposes of mitigating risk facing projects to a very great extent. Thus project risk identification function is established throughout the whole enterprises and insuring against financial loss and develop risk management strategy to allocate resources efficiently and influence less costing of the project.

The study recommends that a further study should be carried out to investigate the effects of other risk management strategies on project performance of SMES not discussed in this study such as risk assessment, risk responses, monitoring and review. A further study should be carried out to determine strategies that should be adopted to maintain the positive effects of risk management strategies on the project performance of construction SMEs.

\section{Acknowledgment}

The authors wish to thank small and medium contractors for participating in this study. Without their participation, this study would not have been conducted. We also wish to acknowledge the financial support from the University of Support in conducting this study.

\section{References}

[1] P. L. Bannerman, (2008). Risk and risk management in software projects: A reassessment. The Journal of Systems and Software , 81(12), 2118-2133.

[2] R. J, Voetsch, D. F., Cioffi, \& F. T Anbari,. (2004). Project risk management practices and their association with reported project success. In Proceedings of 6th IRNOP Project Research Conference, Turku, Finland, $680-697$.

[3] J. C. Parrenas, (2005), The Regulatory and Business Environment for Risk Management Practices in the Banking Sectors of APEC Economies: 
Report of a Collaborative Survey Undertaken by the Pacific Economic Cooperation Council Finance Forum and the Asian Bankers' Association. PP. 1-14.

[4] J. Amos, \& P. Dents, (1997). Risk analysis and management for major construction projects. Proceedings: RICS COBRA 1997 Conference. Portsmouth, September, 1-35.

[5] K.M. Eisenhardt, (1989), Building Theories from Case Study Research. The Academy of Management Review, Vol.14 No 4, pp. 532-550.

[6] N.J Libon (2004). The valuation of risk assets and the selection of risky investments in stock portfolios and capital budgets, Review of Economics and Statistics, 47 (1), 13-37.

[7] W. Addison, \& P. Vallabh, (2002) Impact of project risk Identification performance of software projects in IT enterprises in China. Journal of Project Risk Management, Vol. 8 No 1, pp. 17-24.

[8] I.O. Olamiwale, (2014). Evaluation of risk management practices in the construction industry in Swaziland, Master's Thesis, Tshwane University of Technology, Pretoria-South Africa.

[9] G, Chacko,. \& G. Harris, (2006). Information and Communication Technology and Small, Medium and Micro Enterprises in Asia-Pacificsize does not matter. Information Technology for Development, 12(2): 175-177.

[10] R. Olsson, (2008). Risk management in a multi project environment. International Journal of Quality and Reliability Management, 25, 1, 6071

[11] G. Jun, R. Qiuzhen, \& E. Qingguo, (2010) Effects of project risk planning on IT project performance focusing on a case of China vendor firms. Project Management Journal, Vol. 31 No 1, pp. 32-43.

[12] D. Baloi, \& A.D.F. Price, (2003). Modelling global risk factors affecting construction cost performance. International Journal of Project Management, 21(4): 261-269.

[13] S.D. Santoso, S.O. Ogunlana, \& T. Minato, (2003). Assessment of risks in high rise building construction in Jakarta. Engineering, Construction and Architectural Management, 10(1): 43-55.

[14] X. Wang, \& J. Huang, (2006). The relationships between key stakeholders' project performance and project success: perceptions of Chinese construction supervising engineers, International Journal of Project Management 24, 253-260.

[15] S., Toor, and S. Ogunlana, (2010). Beyond the iron triangle: stakeholder perception of key performance indicators (KPIs) for large-scale public sector development projects, International Journal of Project Management 28, 228-236

[16] M.T Banki,., S., Hadian, M., Niknam, and I. Rafizadeh, (2009). Contractor selection in construction projects based on a fuzzy AHP method. Proceedings of the Annual Conference-Canadian Society for Civil Engineering.

[17] S.T. Ng, Z. Tang, and K. Palaneeswaran, (2009). Factors contributing to the success of equipment-intensive subcontractors in construction, International Journal of Project Management, 27: 736-744.

[18] J., Hinze, S Thurman, and A. Wehle, (2013). Leading indicators of construction safety performance. Safety Science, 51(1):23-28.

[19] J.S., Chou, and A.D Pham,.(2013).Project management knowledge of construction professionals: Cross-country study of effects on project success, Journal of Construction Engineering and Management, 139(11):04013015-1-04013015-15

[20] U., Ojiako, E., Johansen, and D Greenwood,. (2008). A qualitative reconstruction of project measurement criteria, Industrial Management and Data Systems, 108 (3): 405-417.

[21] C M., Weninger.,. Huemann, J.C Oliveira,., L.F.M Barros Filho,., and E. Weitlaner, (2013). Experimenting with project stakeholder analysis: a case study. In: Silvius, A.J.G., Thap, J. (Eds.), Sustainability Integration for Effective Project Management. IGI Global.

[22] F.T., Berssaneti, and M. M Carvalho,. (2015).Identification of variables that impact project success in Brazilian companies, International Journal of Project Management, 33: 638-649

[23] D.K Ahadzie,., D.G Proverbs,., and P.O. Olomolaiye, (2008). Critical success criteria for mass house building projects in developing countries, International Journal of Project Management, 26: 675-687
[24] E., Lam, A., Chan, D. Chan, (2008). Determinants of successful designbuild projects, Journal of Construction Engineering and Management 134 (5): 333-341.

[25] A. L. C. Roelen, and M. B Klompstra,. (2012). The challenges in defining aviation safety performance indicators. Preprint for PSAM II and ESREL, 25-29 June, 2012, Helsinki: Finland

[26] J.S Chou,., and J.G Yang,. (2012). Project management knowledge and effects on construction project outcomes: an empirical study, Project Management Journal, 43 (5): 47-67.

[27] D.P Dingsday,., H.C Biggs,., and D Cipallo,. (2008). Safety effectiveness indicators (SEIs): Measuring construction industry performance. Proceedings Third International Conference of the Cooperative Research Centre (CRC) for Construction Innovation-Clients Driving Innovation: Benefitting from Innovation, Gold Coast, Australia.

[28] H.H Al-Shibly, B.M Louzi,. \& M.A Hiassat..(2013). The impact of risk management on construction projects success from the employees' perspective, Interdisciplinary Journal of Contemporary Research in Business, 5(4):12-43.

[29] Y. Ewer, \& M.M. Mustafa, (2008). The Impact of Risk Management on IS Projects Success in Syria, Proceeding of International Conference on Telecommunication Technology And Applications, 1-6, Damascus.

[30] C.G Martins, (2006). Aplicação das Técnicas de Identificação de Risco em Projetos de E and P. 2006. 93f. Monografia (Pós-Graduação-MBA em Engenharia Econômica e Financeira)-Universidade Federal Fluminense-UFF. Niterói

[31] K. Bakker, A. Boonstra, and H. Wortmann, (2011). Risk management affecting IS/IT project success through communicative action', Project Management Journal, 42 (3):75-90.

[32] B.K Grote,., and M. Moss, (2008). How to measure the effectiveness of risk management in engineering design projects? Presentation of RMPASS: a new method for assessing risk management performance and the impact of knowledge management - including a few results", Research in Engineering Design, 19(2/3):71-100.

[33] J. F Hair, Jr., W. C Black, B. J Babin,., R. E Anderson, and R. L Tatham,. (2006). Multivariate Data Analysis (6th Ed.). Upper Saddle River, NJ: Pearson Prentice Hall

[34] C. Zaiontz, (2014). Real statistics using excel: Cronbach's alpha. Word Press Online

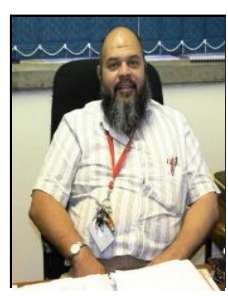

Nazeem Ansary (NHD, BTech QS, MCPM, PrQS, PMAQS, MRICS, MCIOB) holds a National Higher Diploma in Building Surveying and Bachelor's Degree in Quantity Surveying from Cape Peninsula University of Technology, South Africa and Tshwane University of Technology respectively. He received in 2010 his Master's Degree, Master of Construction Project Management from University of New South Wales, Australia. $\mathrm{He}$ is a Professional Quantity Surveyor and has many years of working experience in the construction industry and currently working as a senior lecturer and Head of Department Construction Management and Quantity Surveying at the University of Johannesburg, South Africa. He has published several accredited articles in refereed journals and has presented papers in many international conferences all over the world. His main research interests are construction project management, construction management, dispute resolution, risk management in construction.

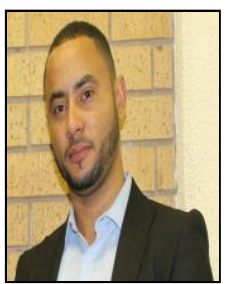

Berenger Y. Renault was born in Gabon on June 26, 1989. He obtained his National Diploma in Construction Management and Quantity Surveying and Bachelor's Degree in Quantity Surveying from University of Johannesburg, South Africa in 2012 and 2014 respectively. He has been a Tutor at the Faculty of Engineering and The Built Environment since 2013. Renault is also a member of the Association of South African Quantity Surveyors. He is currently a Master student at the Department of Construction Management and Quantity Surveying at the University of Johannesburg. His work is animated by an interest in the area of risk management. 